\title{
BAL ARISI (Apis mellifera L.) SPERMASININ TAZE VE DONDURULARAK MUHAFAZA EDILMESI
}

\author{
Preserving Honey Bee (Apis mellifera L.) Semen as Fresh and Frozen
}

(Extended Abstract Can be Found at the end of the Article)

\begin{abstract}
Aziz GÜL ${ }^{1}$, Durmuş Ali CEYLAN ${ }^{2}$
${ }^{1}$ Mustafa Kemal Üniversitesi Ziraat Fakültesi Zootekni Bölümü Antakya/Hatay

${ }^{2}$ Selçuk Üniversitesi Çumra Meslek Yüksekokulu Çumra/Konya

Geliş Tarihi: 04.02.2017 Kabul Tarihi: 02.03.2017

ÖZ

Arıcılık dünya üzerinde çok eski dönemlerden beri yapılmakta olup çeşitli tarım kolları ile birlikte uyumlu bir şekilde toprağa bağlı kalınmaksızın yapılabilen bir yetiştiricilik koludur. Bilim ve teknolojinin gelişmesi ile yakın geçmişten günümüze balarılarının yaşamları aydınlatılmıştır. Balarılarında üremenin izahı 1845 yılında yapılmış olup, 1926 yılında balarılarında suni tohumlamanın keşfi ile birlikte arıcılık sektörü hızlı bir şekilde ilerlemiştir. Suni tohumlama ile birlikte balarısı spermasının depolanılabilirliği üzerinde çalışmalar da $1960^{\prime} ı$ yıllarda başlamıştır. Günümüzde, balarısı sperması taze olarak $16^{\circ} \mathrm{C}$ 'de 2 hafta gibi bir süre canlı olarak muhafaza edilebilmektedir. Dondurma işleminde ise tam bir başarı elde edilmiş değildir. Günümüzde depolanmış sperma ile döllenen anaarılarda \%50'nin üzerinde işçi arı oranı elde edilmesine rağmen, spermanın saklanması konusunda metotların geliştirilmesine intiyaç duyulmaktadır.
\end{abstract}

Anahtar Kelimeler: Balarısı, sperma, taze depolama, dondurma, sıvı azot

\section{ABSTRACT}

Beekeeping has been practiced throughout the world since ancient times and it can be done in a harmony with various agricultural branches without adhering to the soil. With the development of science and technology, the daily lives of honey bees have recently been explained. The explanation of honey bees' breeding was made in $\mathbf{1 8 4 5}$ and the beekeeping sector progressed rapidly with the discovery of artificial insemination in 1926. Scientists also began working on the storage of honey bees' sperm in the 1960s after the discovery of artificial insemination. Today, honey bees' sperm can be kept alive for two weeks at $16^{\circ} \mathrm{C}$, however, it hasn't been a complete success in the freezing process. Although there was a $50 \%$ success rate producing worker bees after the frozen-thawed process, the freezing methods need to be improved.

Key words: Honey bee, sperm, fresh storage, freezing, liquid nitrogen

\section{GíRiş}

Balarıları bal, balmumu, propolis, arı zehri ve arısütü gibi ekonomik öneme sahip birçok ürünün üreticileri olması yanında sayısız tarımsal ürün ve yabani bitkinin de ana dölleyicileridirler. İnsan tüketimine sunulan meyve ve sebzelerin 1/3'ü balarılarının da içerisinde bulunduğu tozlayıcı böcekler tarafından tozlanmakta olup balarıları bu bitkilerin \%80'inin polinasyonunda rol oynamaktadır (FAO, 2016). Ayrıca, tropikal bitkilerin yaklaşık yarısının tozlaşmasını sağlamaktadır (Abdelkader ve ark., 2014). Balarıları tozlaşmadaki etkilerinden dolayı modern tarımın sürdürülmesinde önemli role 


\section{DERLEME MAKALESI /REVIEW ARTICLE}

sahiptirler. Bitkisel üretimde tozlanmaya sağladığı tozlayıcı katkısından dolayı bazı ülkelerde tozlaşmada kullanılmakta ve arıcılar için ek bir gelir kaynağı oluşturmaktadır. Örneğin Kaliforniya eyaletinde (ABD) bulunan badem ve takiben narenciye bahçeleri için yıllık 1.7 milyon bal arısı kolonisi kiralanmaktadır (Rucker ve ark., 2012).

Balarıları sosyal yaşantıları sebebi ile diğer canlılardan farklılıklar göstermektedir; doğaya faydalarının yanında sosyal yaşantıları da araştırıcıların dikkatini çekmiştir. Bazı böceklerin dişileri özel organlarında spermayı birkaç yıla kadar saklayabilmektedirler. Depolama organları yapısal olarak koruyucu, besleyici, kimyasal olarak stabil bir çevre ve sperm canlılığını koruyacak bir yapıdadır (Choe ve Crespi, 1997; Neubaum ve Wolfner, 1999). Balarılarında çiftleşme, diğer böceklerden farklı olarak anaarının yüksükten çıkmasını takiben bir hafta içerisinde olmaktadır. Ancak hava koşullarına bağlı olarak yeterli sperm depo edilememesi durumunda, ikinci bir çiftleşme olabilmektedir. Doğal eşleşme sonrası dişi genital kanala bırakılan sperma yumurta kanalından geçerek 24 saat içerisinde spermatekaya ulaşmakta ve burada anaarının tüm yaşamı boyunca canlıığını korumaktadır (Genç ve Dodoloğlu, 2011). Sosyal böceklerin yaşantıları ve vücutlarındaki bu özel yapılar incelenerek diğer hayvanlarda olduğu gibi böceklerin de spermlerinin depolanabilirliği yıllardır birçok bilim adamı tarafından araştırılmıştır (Taber ve Blum, 1960; Harbo, 1976, 1979, 1983; Melnichenko ve Vavilov, 1976; Verma, 1983; Kaftanoğlu ve Peng, 1984, Hopkins ve Herr, 2010; Wegener ve ark., 2014).

Yeryüzünde sayısız balarısı değerli alttür ve nadir ekotipleri, tarımda pestisitlerin kullanımı ve arazi işlemedeki değişiklikler gibi insanoğlunun sürdürdüğü aktiviteler sonucu tehdit altındadır (James ve Pham Delegue, 2002). Bu gibi tehditlerden dolayı, tehditlerin en aza indirilmesinin yanında, balarılarının spermasının dondurularak sıvı azot içerisinde uzun süre depolanması da önem kazanmıştır. Günümüzde ıslah amacıyla farklı hayvan türlerine ait, sperma veya döllü-dölsüz yumurta gibi materyaller dondurularak kullanılmaktadır. Balarılarında da tür ve ırkların korunması kaliteli gen kaynaklarının saklanması ve yaygınlaştırılması için spermanın dondurularak korunması doğa, tarım, arı ve anaarı üreticileri için son derece önemlidir (Hopkins ve ark. 2012).
Balarısı spermasının dondurulmasına ait ilk çalışmalar 1970 ve 1980 'li yıllarda yapılmıştır (Harbo, 1979, 1983; Kaftanoglu ve Peng, 1984). Ancak bu ilk çabalarda depolanmış sperma ile suni tohumlanan anaarılardan kısmen başarı elde edilmiştir. İlk olarak Taber ve Blum (1960) çalışmalarında, balarısı spermasının oda sıcaklığında 68 gün boyunca depolandıktan sonra anaarıların suni olarak tohumlanabildiğini bildirmişlerdir. Ancak sonuçların başarılı sayılabilmesi için anaarıların \%50'sinin döllenmiş yumurta bırakması gerektiğini bilirtmişlerdir. Çalışmada depolanmış sperma ile döllenen 105 anaarıdan 31 tanesinin ancak döllü yumurta bıraktığını bildirmişlerdir. Benzer şekilde Jaycox (1960) yaptığı çalışma ile balarısı spermasını cam kapiller tüpler içerisinde $35^{\circ} \mathrm{C}$ 'de depolamıştır. Araştırıcı hiçbir şekilde bir ek solüsyon kullanmadan 22 gün boyunca spermlerin canlı kaldığını tespit etmiştir.

Kaftanoğlu ve Peng (1984) yaptıkları bir çalışmada, balarısı spermasının sıvı azot içerisinde bir yıl veya daha uzun süre ile depolanabileceğini tespit etmişlerdir. Ancak depolanmış sperma ile döllenen anaarıların yeterli işçi arı yumurtası bırakmadığı ve koloninin anaarısı olması için verimli olmadığını, depolama için daha etkili depolama solüsyonların geliştirilmesi gerektiğini bildirmişlerdir.

Almeida ve Soares (2002) yaptıkları çalışmalarında, balarısı spermasını hindistancevizi suyunda 120 . güne kadar depolamışlardır. Ancak çalışma sonucunda spermlerin 80 . güne kadar canlı kalabildikleri ve yalnızca 15 gün depo edilen spermanın suni tohumlamada kullanılabildiğini bildirmişlerdir. Araştırıcılar çalışma sonucunda bu yöntemin in vitro olarak balarısı spermasının kısa sureli depolanmasında kullanılabileceğini bildirmişlerdir.

Hopkins ve Herr, 2010 yılında sperma depolama konusunda çok kapsamlı bir çalışma yürütmüşlerdir. Araştırıcılar Koruyucu çözeltilerin toksititesini, sıcaklık hassasiyetlerini, donma oranını ve soğuk şokun etkilerini araştırmışlardır. Çalışma sonucunda en fazla sperma canlılı̆ının (\%93) programlanabilir donma oranını $2^{\circ} \mathrm{C} /$ dak olduğu ve \%10 DMSO kullanılan grupta olduğunu tespit etmişlerdir. Ayrıca spermanın $4^{\circ} \mathrm{C}$ üzerindeki sıcaklıklara toleranslı olduğunu bildirmişlerdir.

Wegener ark., (2014), balarısı spermasının dondurulmasında kullanılan DMSO gibi koruyucu maddelerin hipertonik etkilerine karşı diyaliz 


\section{DERLEME MAKALESİ /REVIEW ARTICLE}

yöntemi geliştirmişlerdir. Ayrıca spermanın dondurularak çözülmesi sonucunda sperma örneklerinin içerisindeki koruyucu kimyasalların olumsuz etkilerini azaltmak için çözülen spermayı santrifüj ederek dondurma esnasında kullanılan koruyucu kimyasalları ayırmışlardır. Bu işlemler sonucunda koruyucu çözeltilerin direkt katılması, spermanın koruyucular içerisinde diyaliz edilmesi ve diyaliz ile birlikte santrifüj işlemi sonucunda elde edilen işçi arı oranlarını sırasıyla \%45.7 (29.277.8), \%47.5 (25.6-72.5) ve \%27.0 (0.5-65.3) olarak belirlemişlerdir.

\section{ERKEK ARILARDAN SPERMA TOPLAMA}

Balarısı spermasının taze veya dondurularak saklanmasının ilk aşaması spermanın sağlıklı bir şekilde erkek arılardan toplanmasıdır (Resim 1). Sperma toplamak için erkek yetiştirme kolonileri belirlenmeli ve bu koloniler takviye besinlerle beslenerek kolonin işçi arı mevcudu yüksek tutulmalıdır. Ayrıca erkek yetiştirme kolonilerinin varroa mücadelesi de etkili bir şekilde yapılmalıdır. Varroa parazitinin erkek arı petek gözlerini tercih ettiği ve varroa ile bulaşık kolonilerdeki erkek arı semen kalitesinin düşük olduğu unutulmamalıdır (Goodvin ve Eaton, 2001). Suni tohumlama Şırıngasında spermanın toplanması esnasında kullanılan serum fizyolojik solüsyonuna alternatif olarak Kiev solüsyonu (100 ml saf su içerisine: Trisodyum citrate-2 hydrate, $2.43 \mathrm{~g} ; \mathrm{NaHCO}_{3}, 0.01$ $\mathrm{g} ; \mathrm{KCl}, 0.30 \mathrm{~g}$; glikoz, $0.30 \mathrm{~g}$ ), ringer solüsyonu $(100 \mathrm{ml}$ saf su içerisine: $\mathrm{NaCl}, 0.85 \mathrm{~g} ; \mathrm{KCl}, 0.025 \mathrm{~g}$; $\mathrm{CaCl}, 0.030 \mathrm{~g}$; glikoz, $0.50 \mathrm{~g}$ ve saf su, $100 \mathrm{ml}$ ) vb. birçok kimyasal bileşim kullanılabilmektedir (Harbo, 1985; Cobey ve Schley, 2002; Güler, 2006). Ancak 2012 yılında Hopkins ve ark. (2012) tarafından geliştirilen sulandırıcı $(100 \mathrm{ml}$ saf su içerisine: $\mathrm{Na}_{2} \mathrm{HPO}_{4} 0.014196 \mathrm{~g}$; sodium citrate $0.03 \mathrm{~g} ; \mathrm{KCl}$ $0.6113 \mathrm{~g} ; \mathrm{NaCl} 0.49 \mathrm{~g} ; \mathrm{NaHCO}_{3} 0.042 \mathrm{~g} ;$ TES buffer $0.6878 \mathrm{~g}$; Tris base $0.3634 \mathrm{~g}$; EDTA 0.00037 $\mathrm{g}$; bovine serum albumin $2 \mathrm{mg}$; proline $0.04950 \mathrm{~g}$; catalase $0.5 \mathrm{mg}$; arginine $0.01 \mathrm{~g}$; glycine $0.00075 \mathrm{~g}$; $10 \mu \mathrm{l}$ Gentamycine; $25 \mu \mathrm{l}$ Streptomycin; $20 \mu \mathrm{l}$ penicillin) hem sperma dondurma solüsyonu olarak, hem de sperma toplama ve anaarıların tohumlanması esnasında iyi sonuçlar vermektedir. Solüsyon hazırlandıktan sonra $0.22 \mu$ l.lik filtreden geçirilerek kullanılmalıdır. Arıcılıkta suni tohumlama işleminde veya spermanın dondurulması esnasında dikkat edilecek diğer önemli bir konu da ortamın sterilizasyonudur. Çalışma alanının hijyenik olması çalışmanın başarısı üzerine doğrudan etkilidir. Çalışma odasının önceden temizlenmesi kullanılacak alet ve ekipmanların \%70'lik etil alkol ile sterilize edilmesi olası mikrobik bulaşmayı büyük ölçüde engellemektedir.
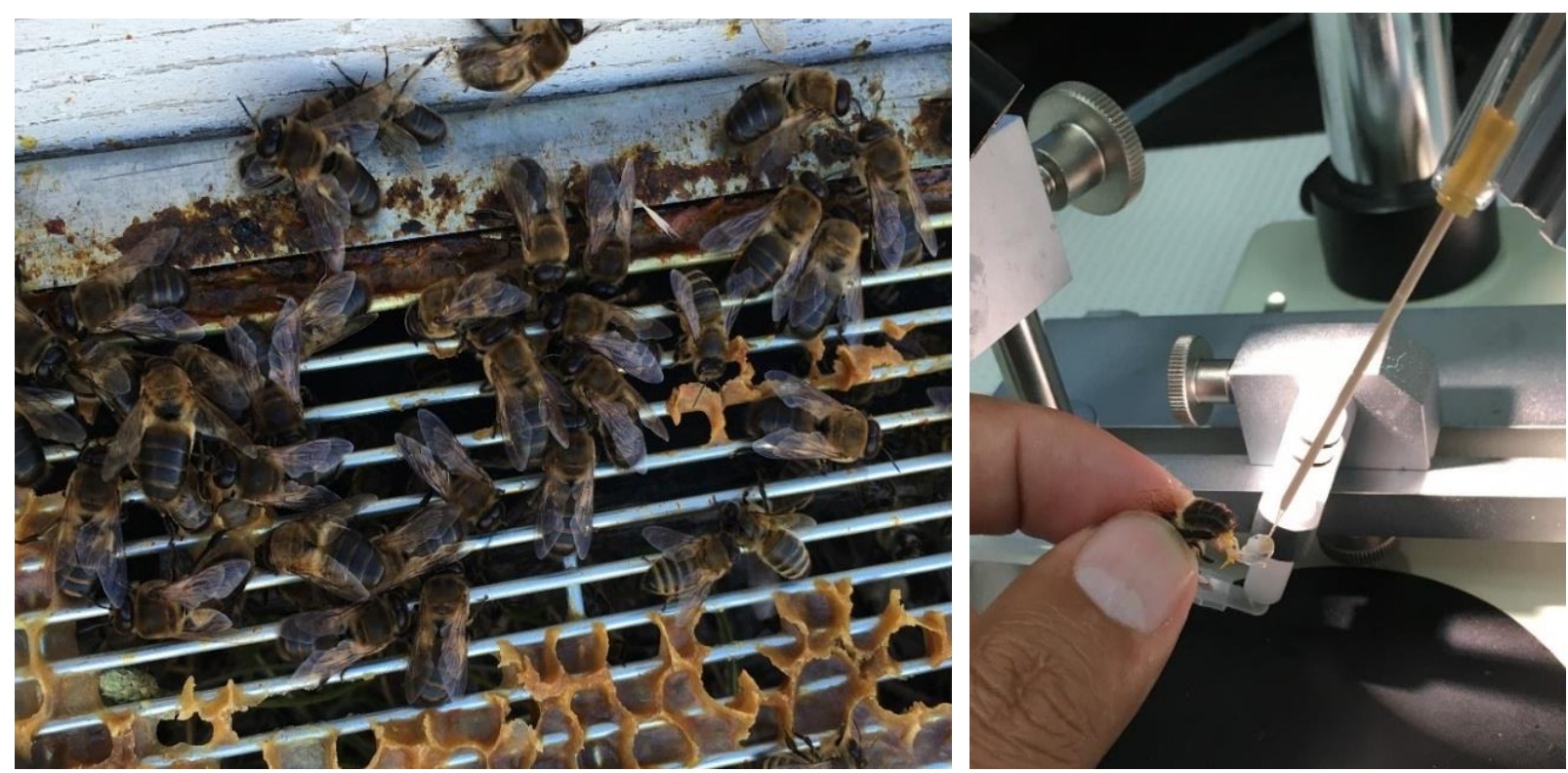

Resim 1. Kovan giriş deliği önünden erkek arıların alınması ve sperma toplanması. 


\section{DERLEME MAKALESI /REVIEW ARTICLE}

\section{BALARISI SPERMASININ TAZE OLARAK SAKLANMASI}

Balarısı sperması kapiller tüpler içerisinde veya toplandığı suni tohumlama iğneleri içerisinde $16^{\circ} \mathrm{C}$ 'de 2 hafta kadar taze olarak muhafaza edilebilmektedir (Almeida ve Soares, 2002; Cobey, 2007). Ancak, spermanın erkek arılardan toplanması esnasında kullanılan serum fizyolojik veya diğer sulandırıcıların içerisine olası mikrobik bulaşmayı ve yayılmasını engellemek amacı ile gentamycine, streptomycin, tylosin ve penicillin benzeri antibiyotikler katılır. Sperma toplama işlemi bittikten sonra kapiller tüplerin veya iğnelerin her iki tarafı spermaya bulaşmayacak şekilde vazelin benzeri mumsu bir madde ile hava almayacak şekilde kapatıır (Resim 2). Ülkelerarası veya bir ülkede iller arasında uzun mesafeler taşınacak olan sperma örnekleri de aynı şekilde muhafaza edilerek düşük sıcaklıkta taşınabilir. Ancak 1-2 gün gibi kısa süre muhafaza edilecek olan spermalar için kapiller tüplerin veya iğnelerin her iki tarafına bir miktar sulandırıcı çekilmesi yeterlidir. Ayrıca, spermanın 2 hafta gibi uzun süreli muhafazalarında kapiller tüpler olası ısı farklıı̆ğı ve ışığın olumsuz etkilerinden korunması amacıyla alüminyum folyo vb. bir madde ile kaplanır.
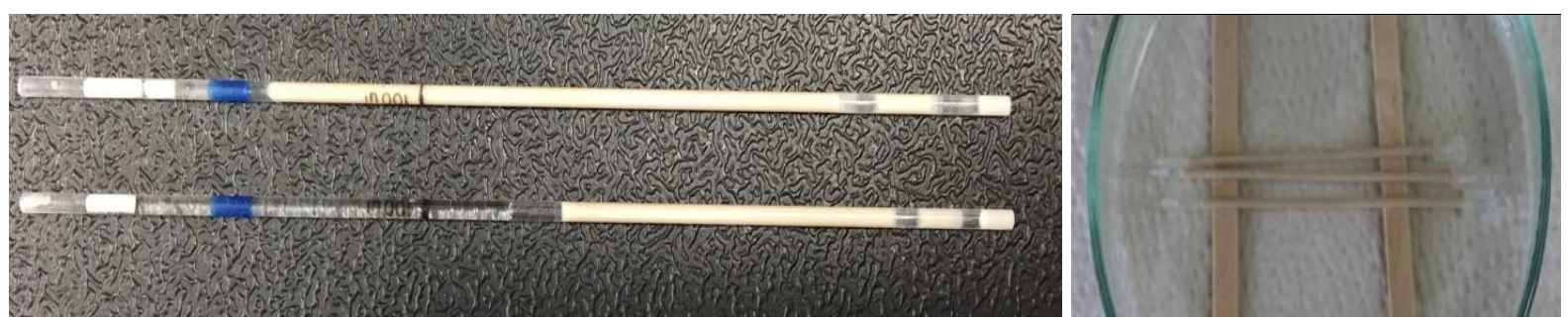

Resim 2. Cam kapiller tüpler ve suni tohumlama şırınga iğnesi içerisinde depolanan sperma.

\section{BALARISI SPERMASININ DONDURULARAK SAKLANMASI}

Balarısı spermasının dondurularak saklanması genelde diğer çiftlik hayvanlarında olduğu gibi 0.25 mllik payetler içerisinde yapılmaktadır. Sperma örnekleri payetlere doldurulmadan önce koruyucu solüsyonlarla sulandırılıktan sonra payetlere çekilir. Balarısı sperması ilk olarak bir miktar sulandırıcı (5 birim sperma: 1 birim sulandırıcı) ile sulandırılır. Daha sonra karışımın pH ve ozmotik basınç dengesini korumak amacı ile buffer solüsyonları, dondurulma esnasında hücre içi buzlanmayı engellemek amacı ile hücre içi suyu uzaklaştırmak için Dimethyl sulfoxide (DMSO) ve tercihe göre yumurta sarısı katılır. Tüm karışım hazırlandıktan sonra spermanın her iki tarafında 4-5 $\mathrm{mm}$ boşluk olacak şekilde sırasıyla sulandırıcısperma- sulandırıcı payete çekilir ve payetin pamuk olmayan tarafı herhangi bir sıcak baskı veya kapama tozu ile kapatılır (Resim 3, Resim 4). Dondurmanın başarısı üzerinde hücre içi kristalizasyonu engellemek amacı ile sulandırıcıya katılan koruyucu maddelerin konsantrasyonu ve çeşidi, soğutma hızı ve soğuk şoku, genel sıcaklık duyarlılıkları önemli bir etkiye sahiptir (Hopkins ve Herr, 2010).

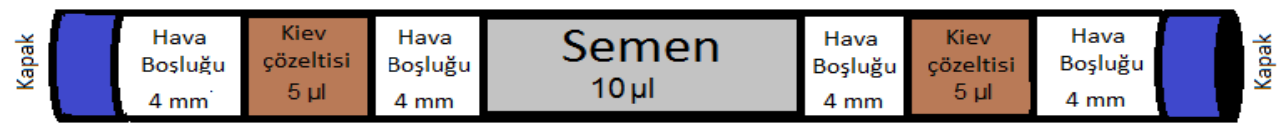

Resim 3. Payetlere spermanın doldurulma şekli. 


\section{DERLEME MAKALESI /REVIEW ARTICLE}
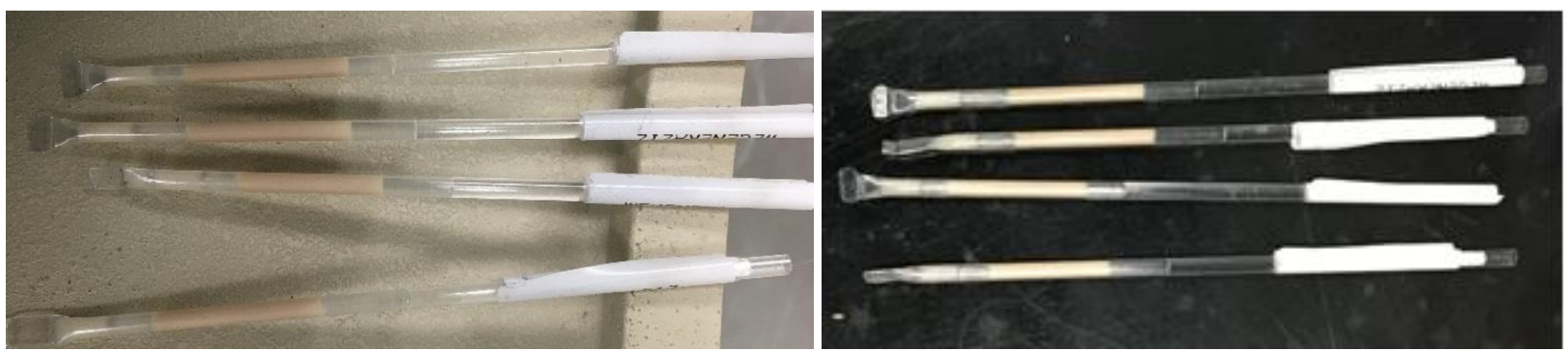

Resim 4. Plastik payetlere $(0.25 \mathrm{ml})$ çekilmiş ve doldurulmaya hazır bal arısı sperması.

Hazırlanan payetler ilk aşamada katılan DMSO'nun hücre içi sıvı ile yer değiştirmesi ve ısının stabilizasyonu amacıyla $+5^{\circ} \mathrm{C}$ 'de 2 saat kadar ekilibrasyonda bekletilir. Bu süre sonunda payetler alınarak kademeli dondurma cihazı haznesine yerleştirilir (Resim 5). Cihazın programlaması $3^{\circ} \mathrm{C} / \mathrm{dk}$ soğuyacak şekilde $-40^{\circ} \mathrm{C}$ 'ye soğuyacak şekilde programlanır (Hopkins ve ark., 2012; Wegener ve ark., 2014). Sicaklık $-40^{\circ} C^{\prime}$ ye ulaştığında sperma örnekleri seri bir şekilde alınarak sıvı azot tankları içerisine yerleştirilerek kullanılıncaya kadar burada muhafaza edilir (Resim $6)$.
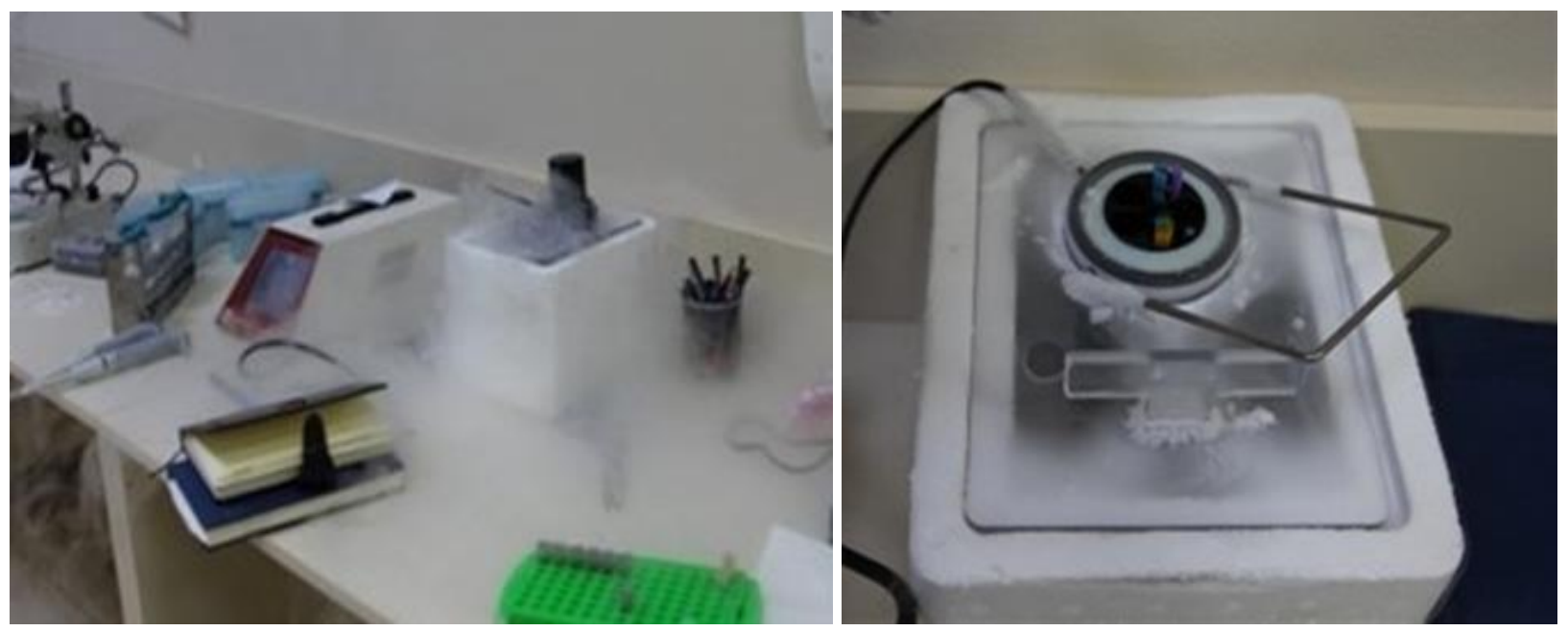

Resim 5. Kademeli dondurma cihazında dondurma işlemi.

Spermanın dondurulması amacıyla kullanılan sulandırıcıların eritme sonrası canlılık üzerine önemli etkileri bulunmaktadır. Dimethyl sulfoxide (DMSO), ethylene glycol, dimethylacetamide (DMA) ve glycerol balarılarında kullanılan başlıca kriyoprotektanlar olup bunlar içerisinde en etkili olanı ve en fazla kullanılan koruyucu DMSO'dur (Taylor ve ark., 2009). Kriyoprotektanlar genelde hücre içi buzlanmayı engelleyici etkiye sahiptirler (Watson ve Fuller, 2001). Ancak yumurta sarısı sperma depolama çalışmalarında kullanıımış (Hopkins ve ark., 2012) ve iyi sonuçlar alınmış olsa bile spermanın çözülerek anaarılara tohumlama yapıldıktan sonra anaarının ovariol kanallarını tıkadığı ve olumsuz etkileri olduğu yönde şüpheler de bulunmaktadır (Wegener ve ark., 2014). 


\section{DERLEME MAKALESI /REVIEW ARTICLE}
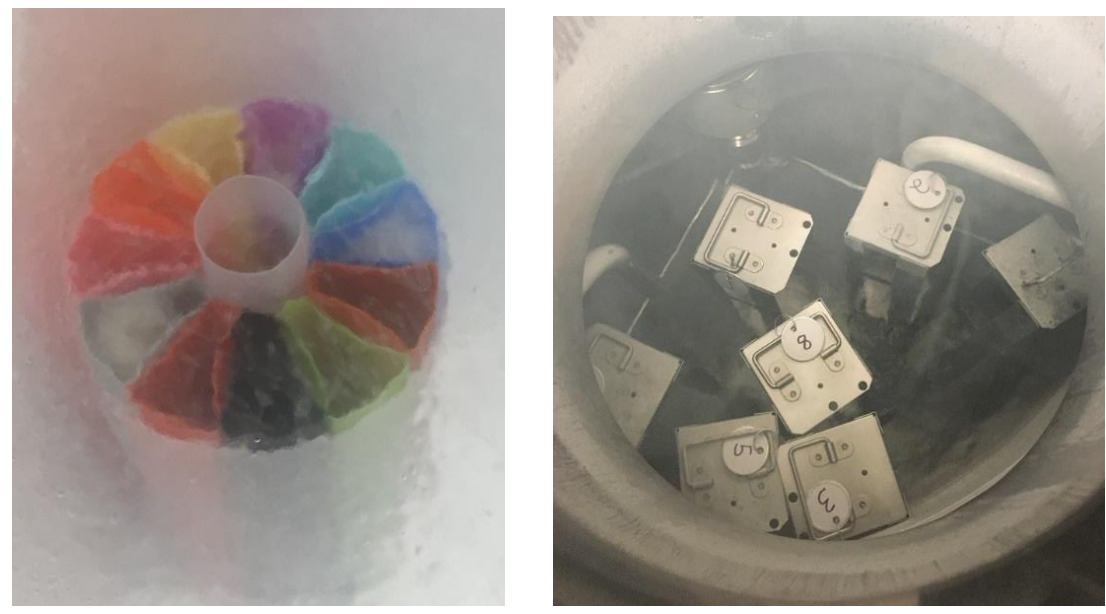

Resim 6. Azot tankı içerisinde spermanın dondurulmuş halde muhafazası.

Başka bir dondurma yöntemi olan ve diğer çiftlik hayvanları spermasının dondurulmasında uygulanabilen vitrifikasyon yöntemi, balarısı sperması için uygun bir dondurma yöntemi değildir. Hızlı dondurma yöntemlerinde balarısı spermlerinin yaşadığı ani soğuk şokları dondurma esnasında ölü sperm sayısının artmasına sebep olmaktadır (Hopkins ve ark., 2012; Wegener ve ark., 2014). Bu sebeple balarısı sperması için kademeli dondurma yöntemi idealdir.

\section{DONDURULMUŞ SPERMANIN ÇÖZÜLMESI VE SUNI TOHUMLAMA}

Dondurulmuş sperma kullanılacağı zaman seri bir şekilde sıvı azot içerisinden alınır ve $35-40^{\circ} \mathrm{C}$ sıcaklıktaki su içerisine daldırılır. Su içerisinde hafif sallanarak 20 saniye kadar tutulur (Hopkins ve ark., 2012). Daha sonra steril bir ortama alınarak sterilize edilmiş bir makas ile payetin her iki tarafı kesilir ve suni tohumlama şırıngasına aktarılarak tohumlama yapılır. Tohumlamadan önce bir lam üzerine $1 \mu \mathrm{l}$ kadar çözülmüş sperma örneği alınır ve mikroskop altında motilitesi belirlenir (Resim 7). Ayrıca ölü/canlı sperm oranı (Resim 8) vital boyama yöntemi ile belirlenir. Canlı sperm hücre sayısı ve motilite skorları yüksek (4-5) sperm örnekleri anaarıların tohumlamasında kullanılır.

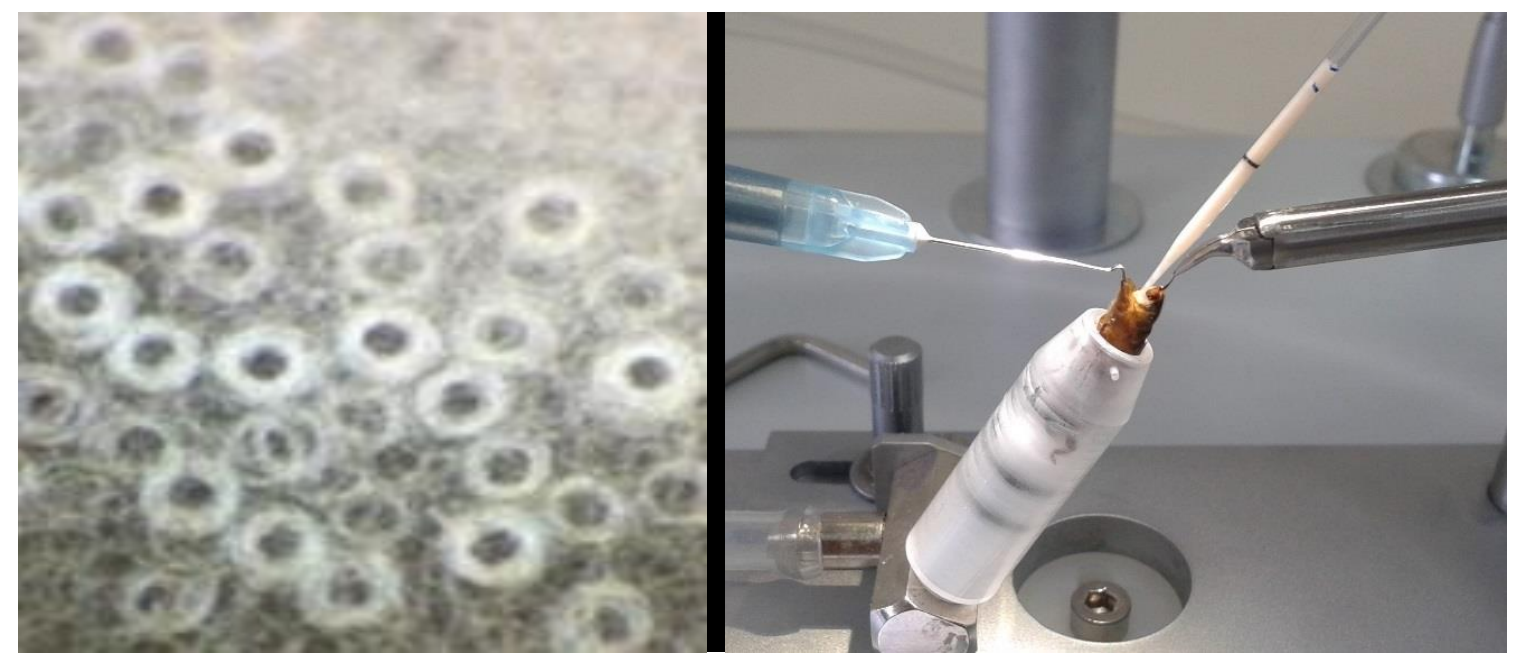

Resim 7. Dondurma işlemi sonrasında motil spermanın görünüşü ve anaarının tohumlanması. 


\section{DERLEME MAKALESI /REVIEW ARTICLE}
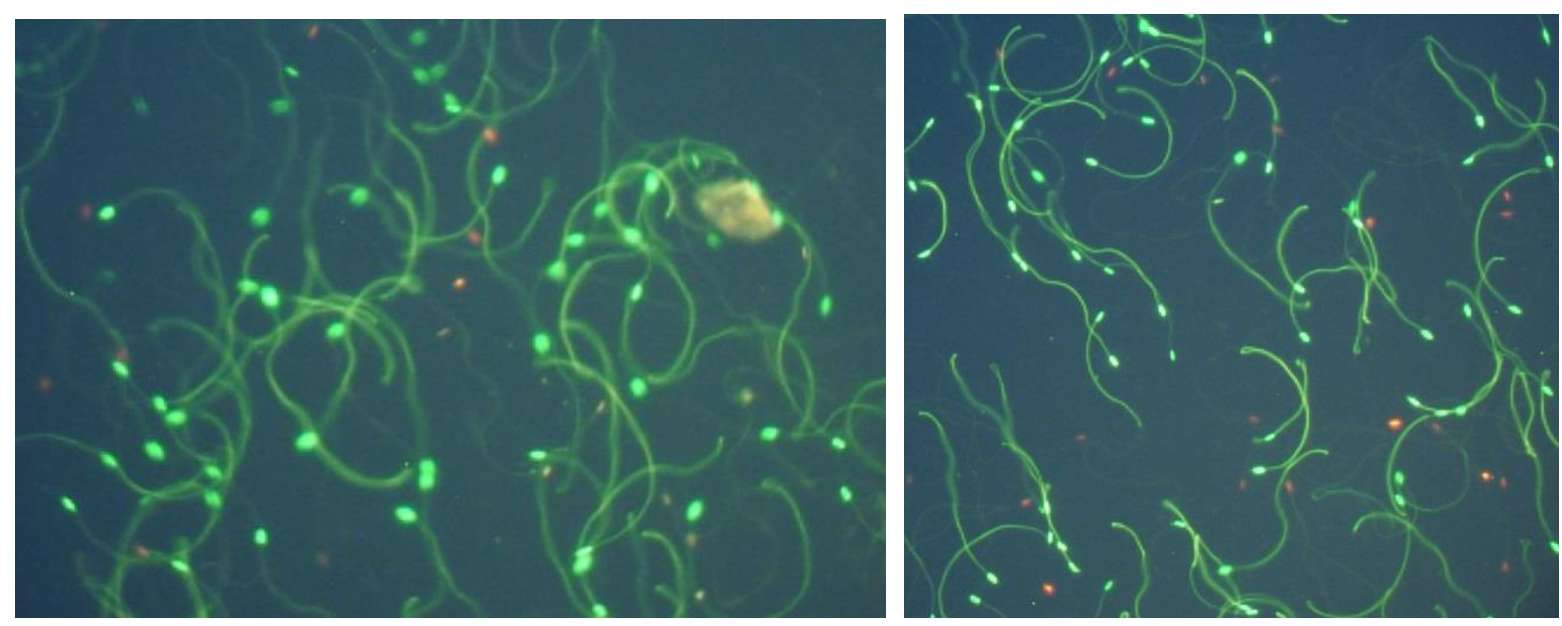

Resim 8. Dondurma işlemi sonrasında vital boyama ile ölü (kırmızı) ve canlı (yeşil) sperma testi

\section{SONUÇ}

Diğer çiftlik hayvanlarında sahada rahatıkla kullanılacak şekilde geliştirilmiş olan sperma dondurma işleminin balarılarında da aynı düzeye ulaşması arıcılık sektörüne de benzer kolaylıklar sağlayacaktır. Günümüzde sığırlarda 37 yıldır depolanmış olan sperma örneklerinin çözüldüklerinde normal bir motiliteye sahip oldukları görülmüş ve başarılı bir şekilde in vitro döllemede kullanılmıştır (Leibo ve ark., 1994). Genetik materyallerin dondurulmasının geçmişi çok eski olmamasına rağmen, şu ana kadar elde edilmiş verilere göre sıvı azot içerisinde sperma veya embriyoların muhafazası uzun süre yapılabilecektir. Ancak sperma dondurma işlemi balarısı sperması için ayrı bir zorluk teşkil etmektedir. Diğer çiftlik hayvanlarında milyonlarca sperma içeren her bir payet bir dişi için kullanılmakta ve payetteki tüm sperma bir yumurtayı döllemek için rekabet etmektedir. Dolayısı ile dondurma başarısı çok düşük olsa bile yumurtanın döllenmesi kuvvetle muhtemeldir. Ancak balarılarında durum çok farklıdır. Anaarının yumurtladığı her yumurtanın döllenmesi için sperm kesesinde depolanan spermadan 5-30 arasında sperm kullanılmaktadır. Dolayısı ile dondurulan balarısı spermlerinde canlılık ve motilitenin çok yüksek olması gerekmektedir. Ayrıca dondurma ve çözme işleminden sonra canlı ve ölü spermleri ayırma metotlarının geliştirilmesi de önem arz etmektedir. Mevcut çalışmalar ile dondurma sonrası elde edilen işçi arı oranları genetik materyallerin korunması için yeterli olsa da özel sektörde uygulanacak düzeyde değildir. Dondurma yöntemlerinin geliştirilmesi ve ölü/canlı sperm ayırımı ile yüksek oranda işçi arı elde edilmesi metodun ticari arıcilıkta da kullanılmasına imkan sağlayacaktır.

\section{KAYNAKLAR}

Abdelkader F.B., Kairo G., Tchamitchian S., Cousin M., Senechal J., Crauser D., Vermandere J.P., Alaux C., Conte Y.L., Belzunces L.P., Barbouche N., Brunet, J.L. 2014. Semen quality of honey bee drones maintained from emergence to sexual maturity under laboratory, semi-field and field conditions. Apidologie, 45 (2), 215-223.

Almeida, R., Soares, A. E. E. 2002. Usage of green coconut water and different tissue culture media for in vitro honey bee semen storage (Apis mellifera; Hymenoptera: Apoidea). Interciencia, 27, 317-321.

Cobey, S., Schley, P. 2002. Innovation in instrumental insemination. The compact, versatile right and left handed Schley model II instrument. Ohio State University 1735 Neil Ave. Columbus, Ohio USA.

Cobey S. 2007. Comparison studies of instrumentally inseminated and naturally mated honey bee queens and factors affecting their performance. Apidologie, 38, 390-410

Choe, J C., Crespi, B J. 1997. The Evolution of Mating Systems in Insects and Arachnids, Cambridge University Press. Cambridge. Pp: 385. 


\section{DERLEME MAKALESI /REVIEW ARTICLE}

FAO. 2016. Food and Agriculture Organization, Pollinators. Retrieved from http://www.fao.org/ biodiversity/ components/pollinators/en/

Genç, F., Dodoloğlu A. 2011. Arıcılı̆ı̆n Temel Esasları. Erzurum: Atatürk Üniversitesi Yayınları.

Güler, A. 2006. Bal arıları (Apis mellifera L.)'nda yapay tohumlama ve Türkiye için önemi. OMÜ Zir. Fak. Dergisi, 2006, 21(3): 370-378

Goodvin, M., Eaton V. C. 2001. Control of Varroa. A Guide for New Zealand Beekeepers.

Harbo, J.R. 1976. "Survival of honey bee spermatozoa in Liquid Nitrogen". Ann. Entomol. Soc. Am. 70, 257-258.

Harbo, J.R. 1979. "Storage of honey bee spermatozoa at $-196^{\circ} \mathrm{C}$ ". J. Apic. Res. 18, 57-63.

Harbo, J.R. 1983. "Survival of honey bee (Hymenoptera: Apidae) spermatozoa after two years in liquid nitrogen (-196 $\left.{ }^{\circ} \mathrm{C}\right)$ ". Ann. Entomol. Soc. Am, 76, 890-891.

Harbo, J.R. 1985. Instrumental insemination of queen bee. Stock Center Laboratory. ARS, USDA, Route 3, Ben Hur Road, Baston Rouge, LA 70820.

Hopkins, B.K., Herr, C. 2010. Factors affecting the successful cryopreservation of honey bee (Apis mellifera) spermatozoa. Apidologie, 41(5), 548-556.

Hopkins, B.K., Herr, C., Sheppard, W.S. 2012. Sequential generations of honey bee (Apis mellifera) queens produced using cryopreserved semen. Reproduction, Fertility and Development. 24 (8), 1079-83.

James, D., Pham-Delegue, M.H. 2002. Honey Bees: Estimating the Environmental Impact of Chemicals. Book. Retrieved from http://www.amazon.co.uk/Honey-Bees-

Estimating-Environmental-Chemicals/dp/ 0415275180

Jaycox, E.R. 1960. The effect of drying and various diluents on spermatozoa of honey bee. J. Econ. Entomol. 53 (2), 266-269.

Kaftanoglu, O., Peng, Y.S. 1984. Preservation of honeybee spermatozoa in liquid nitrogen. Journal of Apicultural Research. 23 (3), 157-163.

Leibo, S.P., Semple M.E., Kroetsch T.G. 1994. "In vitro fertizilation of oocytes by 37 year-old cryopreserved bovine spermatozoa". Theriogenology, 42,1257-1262.

Melnichenko, A.N., Vavilov Y.L. 1976. "Long term storage of drone semen by freezing in liquid nitrogen SP S Kennan". Soviet Agric. Sci. 1, 34-36.

Neubaum, D.M, Wolfner M.F. 1999. Wise, winsome, or weird Mechanisms of sperm storage in female animals. Curr Topics Dev Biol. 41, 67-97.

Rucker, R. R., Thurman, W. N., Burgett, M. 2012. Honey bee pollination markets and the internalization of reciprocal benefits. American Journal of Agricultural Economics, 94 (4), 956-977.

Taber, S., Blum M.S. 1960. "Preservation of honey bee semen". Science, 131 (3415), 17341735.

Taylor, M.A., Guzmán-Novoa, E., Morfin, N., Buhr, M.M. 2009. Improving viability of cryopreserved honey bee (Apis mellifera L.) sperm with selected diluents, cryoprotectants, and semen dilution ratios. Theriogenology. 72 (2), 149-159.

Verma, L.R. 1983. "Effect of deep freezing on the survival of the honey bee (Apis mellifera L.) spermatozoa". Am. Bee J. 123, 851-852.

Watson P F., Fuller B J. 2001. Principles of Cryopreservation of Gametes and Embryos, in: Watson P.F., Holt W.V. (Eds.), Cryobanking The Genetic Resource: Wild life Conservation for the Future?, CRC Press, London,. pp. 21-46.

Wegener, J., May, T., Kamp, G., Bienefeld, K. 2014. A successful new approach to honeybee semen cryopreservation. Cryobiology, 69 (2), 236-42.

\section{EXTENDED ABSTRACT}

Honey bees are social insects that produce honey, pollen, propolis, wax and bee venom, which humans have utilized for thousands of years. In the effort to collect and produce these hive products, honey bees perform arguably their most ecologically important role, pollination, making them a critical component of modern agriculture. Honey bees pollinate more than 100 crop varieties, with an estimated one-third of the human diet being derived from these insect-pollinated plants. Honey bees are 


\section{DERLEME MAKALESI /REVIEW ARTICLE}

responsible for about 80 percent of this pollination around the world.

With the development of science and technology, the daily lives of honey bees have recently been explained. The explanation of honey bees' breeding was made in 1845 and the beekeeping sector progressed rapidly with the discovery of artificial insemination in 1926. Scientists also began working on the storage of honey bees' sperm in the 1960s after the discovery of artificial insemination. Today, honey bees' sperm can be kept alive for two weeks at $16^{\circ} \mathrm{C}$, however, the current freezing process has not been a complete success. Although there was a $50 \%$ success rate producing worker bees after the frozen-thawed process, the freezing methods need to be improved.

While fresh semen can be safely stored a couple weeks, conservation and breeding requires longterm preservation. Liquid nitrogen storage of gametes provides a means for long-term storage of genetic material. Cryopreservation of semen has been used to maintain valuable breeding material for a number of animal species of agricultural importance. Protecting the genetic resources of honey bees by freezing spermatozoa is of great importance as a conservation safety net and breeding tool.

The most critical aspect of collection and abovefreezing storage of semen is the introduction of antibiotics into the sample. Honey bees' sperm is stored which is the same process that is applied in other livestock species in $0.25 \mathrm{ml}$ straws. Before being loaded to straws, semen mixes with extender (5 sperm: 1 extender). Buffer is added to balance the $\mathrm{pH}$ and osmotic pressure, Dimethyl sulfoxide (DMSO) and egg yolk to prevent intracellular freezing during the cooling process. Cryoprotectants have an important role during frezing of germplasms. The working mechanism of cryoprotectant is the same in all cells or ovariol of animals, including honey bees. Although dimethyl sulfoxide (DMSO), ethylene glycol, dimethylacetamide (DMA) and glycerol are common cryoprotectants used in cryo-studies in bee semen, dimethyl sulfoxide (DMSO) is the most effective cryoprotectant in the process of freezing process any type of live cells, including honey bee sperm. 